$\begin{array}{ll}\text { Research Square } & \begin{array}{l}\text { Preprints are preliminary reports that have not undergone peer review. } \\ \text { They should not be considered conclusive, used to inform clinical practice, } \\ \text { or referenced by the media as validated information. }\end{array}\end{array}$

\title{
Meta Analysis of the Influence of Prone Ventilation Duration on the Mortality of Acute Respiratory Distress Syndrome at 28 Days and 3 Months
}

\section{Cuirong Ba ( $\nabla$ bcr428@163.com)}

shou du yi ke da xue fu shu bei jing di tan yi yuan: Capital Medical University Affiliated Beijing Ditan Hospital https://orcid.org/0000-00028241-0841

\section{Xiaoqiang Wang}

Beijing College of Traditional Chinese Medicine: Beijing University of Chinese Medicine

\section{Research}

Keywords: Prone position ventilation, Acute respiratory distress syndrome, Acute lung injury, Case fatality rate at 28 days, 3 months mortality Posted Date: January 15th, 2021

DOI: https://doi.org/10.21203/rs.3.rs-145352/v1

License: (c) (i) This work is licensed under a Creative Commons Attribution 4.0 International License. Read Full License 


\section{Abstract}

Introduction: To evaluate the effect of prone ventilation duration on the mortality of patients with acute respiratory distress syndrome (ARDS) at 28 days and 3 months.

Materials and Methods: Use a computer to search of relevant studies published in PubMed, the Cochrane Library, CBM, CnKI, VIP and Wanfang database on the influence of prone ventilation on the mortality rate of ARDS patients was conducted. Two personnel trained in evidence-based medicine collected literature and extracted data against inclusion and exclusion criteria, and Meta analysis was conducted using RevMan 5.3 software. A total of 29 randomized controlled trials were included, involving 3,617 patients. These studies were divided into the $<8$ hour group, the 8-16 hour group, and the $>=16$ hour group according to according to the duration of prone ventilation.

Results: The total effect value of $28 \mathrm{~d}$ fatality rate was [ $(\mathrm{OR}=0.58,95 \% \mathrm{Cl}(0.46,0.73), \mathrm{P}<0.00001]$. All subgroups and the combined effect were statistically significant. Among the $3 \mathrm{M}$ fatality rates, only>= 16 -hour prone ventilation was statistically significant, and the effect value was $[(\mathrm{OR}=0.59,95 \% \mathrm{Cl}(0.46,0.75), \mathrm{P}<0.0001]$. The $3 \mathrm{M}$ fatality rates of the $8-16$ hour and $<8$ hour groups were not statistically significant. Since there was only one study on 8-16 hour ventilation, only subgroup analysis was performed without combining the statistical values of the three groups.

Conclusion: Prone ventilation can reduce the short-term mortality of ARDS patients, but from a long time (>=3M), only prone ventilation time $>=16$ hours can significantly benefit patients. The registration number will be issued.

\section{Introduction}

Acute respiratory distress syndrome(ARDS) is a respiratory distress, refractory hypoxemia in clinical characteristics of the more common internal medicine critical patients, main show is early pulmonary exudative change and alveolar diffuse lesions, subsequent pulmonary edema, atelectasis, and so on and so forth, serious when only $30 \%$ of the alveolar ventilation ${ }^{[1]}$.The physiological and pathological factors mainly include inflammatory exudation, diffuse alveolar edema, formation or exudation of transparent membrane, etc., which further reduces the alveolar volume for effective ventilation, and the poor distribution of lesions in the lung tissue, thus resulting in reduced lung compliance, increased intrapulmonary shunt, and increased respiratory function consumption ${ }^{[2]}$. Its case fatality rate is very high, accounting for about $10 \%$ of hospitalized patients in intensive Care unit (ICU), $24 \%$ of patients on mechanical ventilation, and the case fatality rate is up to $40 \%{ }^{[3]}$. At present, respiratory support may be the only effective treatment for ARDS, so it is very important to provide a cost-effective and effective respiratory support treatment for ARDS patients.Prone Position ventilation (PPV) undoubtedly has the feature of simplicity and operability, and a large number of studies have proved that it can improve oxygenation in patients in a short period of time obviously ${ }^{[4]}$. However, does it also have a positive effect on the prognosis of ARDS patients? It has been reported that prone ventilation can increase the incidence of adverse events such as pressure ulcers and unplanned extubation ${ }^{[5]}$. Therefore, the minimum daily duration of prone ventilation is more favorable for clinical prognosis, which is worth exploring.In this paper, a meta-analysis was used to evaluate the influence of prone ventilation duration on the 28-day and 3-month mortality rate of ARDS patients, so as to provide reference for clinical treatment.

\section{Materials And Methods}

\subsection{Retrieval Strategy}

The two researchers independently searched from The PubMed, The Cochrane Library, CBM, CnKI, Viper and Wanfang databases for Literatures related to prone ventilation and ARDS patients from building the repository to November 28, 2020, among which RCT literatures were directly retrieved in PubMed.At the same time, the references included in the study were traced to supplement and obtain relevant literature. The retrieval was carried out by the combination of subject words and free words. The words directly fo und by Vip with synonyms of "acute respiratory distress syndrome" and "prone ventilation" were retrieved as free words in Vip and Wanfang databases.Searches were performed using "(respiratory distress *+ acute lung injury *+ARDS+ALI) and (prone position ventilation +PPV)" in CNKI and CBM databases.

(3) The Cochrane Library and PubMed were searched by" ((Severe Acute Respiratory Syndrome[mesh]) OR (acute lung injury[Title/Abstract]) OR respiratory distress* [Title/Abstract]) AND (Prone Position[mesh]) OR prone position*[Title/Abstract] ", and previous relevant reviews were searched and references were tracked for inclusion. If there are any differences, negotiate to resolve them. The document search was completed and prospero registered, with a prospero registration number to be distributed

\subsection{Inclusion and exclusion criteria}


(1) Inclusion criteria: All the scientific research designs are Randomized Controlled Trials (RCTs) with no restriction on the blind method; All patients are adults who have been diagnosed with ARDS according to the effective criteria (in accordance with the 1994 AECC definition or the latest Berlin definition).(3) Patients were intubated or tracheotomized and received mechanical ventilation;The treatment group was treated with prone position ventilation, while the control group was treated with conventional supine position ventilation. The baseline level of subjects in each group was comparable and the sample size was clear.

(2) Exclusion criteria: Repeatedly published literature;Conference papers, abstracts;(3) Data error or incomplete, unable to obtain the evaluation index;Non-chinese or English literature.

\subsection{Outcome Indicators}

The primary outcome measures were 28-day (including an average of around 28 days) and 3-month (including a little more than 3 months) mortality.

\subsection{Literature screening and data extraction}

Two researchers independently read the titles and abstracts of the literature after removing duplicates, excluded the studies that obviously did not meet the inclusion criteria, searched the literatures that might meet the inclusion criteria and read the full text to determine whether they met the inclusion criteria.If there are any differences, negotiate to resolve them.The extracted data include: (1) General data: author's name, year of publication, title and source of literature;(2) Research characteristics: general demographic characteristics of the subjects, study time, baseline comparability, duration of prone ventilation, research results, etc.(3) Outcome indicators: case fatality rate and evaluation time.

\subsection{Quality assessment of included studies}

Two reviewers evaluated the quality of the included literature according to the RCT bias risk assessment tool in the Cochrane systematic review, and the inconsistencies were resolved through consultation. The following aspects were evaluated: random method, blind method, allocation and concealment, selective reporting, other bias, and result data integrity.

\subsection{Data Analysis}

The RevMan 5.3 software provided by Cochrane International Collaboration was used for Meta analysis. Odds ratio (OR) was used for enumeration data, and WMD was used for measurement data. All effects were expressed as $95 \%$ confidence interval $(\mathrm{Cl})$.The heterogeneity between the results of each included study was analyzed by $\mathrm{I}^{2}$ test.According to the CFR statistical time, the analysis was divided into two parts. If both 28-day CFR and 3-month CFR were included in one article, they were included separately. Each statistic was divided into three subgroups ( $<8 \mathrm{~h}, 8$ to $16 \mathrm{~h}, \geq 16 \mathrm{~h}$ to $24 \mathrm{~h}$ ) according to the different ventilation time in prone position. First of all, all Meta analysis with random effects model, If there is statistical homogeneity among the results $\left(P>0.05, l^{2} \leq 50 \%\right)$, the fixed effect model will be switched to observe whether the results have changed and recorded, and then the random effect model will be switched back.If there was statistical heterogeneity between the results of each study ( $\left.P \leq 0.05, I^{2}>50 \%\right)$, only the random-effect model was used for Meta analysis. Meanwhile, funnel plot was drawn to evaluate publication bias.Finally, the sensitivity analysis was carried out after each research object was excluded one by one.

\section{Results}

\subsection{Literature retrieval results}

At the initial detection, 2708 articles were selected separately by two evaluators and cross-checked to reach a consensus, In the end, 29 articles on RCT were included and a total of 3617 ARDS patients were included, among which 1828 were prone position ventilation, supine position ventilation in 1789 cases, among them $\left(\mathbb{Q} \mathbb{Q} \otimes 2018^{[6]}\right)$ since the two groups were used for different ventilation duration, 12 people were in the observation group and 12 people in the control group, and the analysis was calculated according to the grouping. The screening flow chart is shown in Figure 1.

\subsection{Literature quality evaluation}

Page $3 / 11$ 
All the included studies were RCT tests, and there was no difference in baseline data. The basic features of the included literature were shown in Table 1, and the bias risk assessment results of the included studies were shown in Figure 2.

\subsection{Effect Evaluation}

2.3.1 Influence of different duration of prone ventilation on 28-day mortality of ARDS patients

A total of 26 studies reported the effect of prone ventilation on 28-day mortality of ARDS patients.A total of 3454 patients were included, including 1755 patients in prone position and 1699 patients in supine position. According to the different ventilation time in prone position, the study was divided into three subgroups: the $<8$ hour group, the 8-16 hour group and the $>=16$ hour group. The fatality rate days of some studies

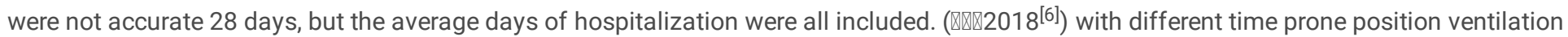
test, so it was conducted in two subgroups for Meta analysis. The random-effect model was used for all the three groups. After testing, the heterogeneity of the three groups was $\left(P=0.03, I^{2}=0 \% ; P=0.003,12=61 \%, P=0.0002,12=0 \%\right.$, overall heterogeneity $(P<0.00001,12=27 \%)$. The differences were statistically significant. When two subgroups without heterogeneity were tested by fixed-effect model, the results showed no significant change.When sensitivity analysis was performed using RevMan 5.3 software (Guerin2013 ${ }^{[11]}$ ), there was heterogeneity in the subgroup analysis, but it was a multicenter study with high quality of evidence and could not be excluded. Beuret2002 ${ }^{[28]}, 8 \nabla 2016^{[27]}$ and 0[ $2013^{[26]}$ may have heterogeneity. Among them, Beuret2002 ${ }^{[28]}$ selected patients were ARDS patients with severe coma, prone time of 4 hours,

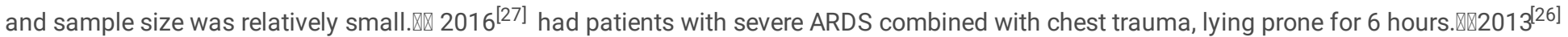
required treatment with fiberoptic bronchoscopy for aspiration lung injury and prone position for 4-6 hours. The heterogeneity may be caused by the different degree of disease, comorbidities and general treatment, but it meets the inclusion criteria and is a baseline comparable randomized controlled trial, so it cannot be ruled out.The $P$ values of the three subgroups in this group were all $<0.05$, and the difference was statistically significant, indicating that prone ventilation can reduce $28 \mathrm{~d}$ fatality rate of ARDS patients regardless of the duration. However, it cannot be said that how long prone ventilation is more beneficial to $28 \mathrm{~d}$ fatality rate. Figure 3 for the forest map and Figure 5 for the funnel map.

\subsubsection{Influence of different duration of prone ventilation on the $3 \mathrm{M}$ mortality rate of ARDS patients}

A total of 15 studies reported the influence of prone ventilation on the $3 \mathrm{M}$ mortality rate of ARDS patients.A total of 2535 patients were included, including 1280 patients in prone position and 1255 patients in supine position.Among them (Taccone2009 ${ }^{[12]}$ ), the outcome of the study was 6-month mortality. Due to its high quality of evidence, the $3 \mathrm{M}$ mortality was incorporated into the study as a long-term efficacy observation. All the studies were divided into three subgroups according to the duration of prone position ventilation, namely the $<8$ hour group, the 8-16 hour group and the $\geq 16$ hour group, and the random-effect model was used for Meta analysis., the heterogeneity of the three groups was $\left(P=0.93, I 2=58 \% ; P=0.72, I^{2}\right.$ could not be calculated (Guerin2004 ${ }^{[18]}$ was the only study); $P<0.0001$, $\left.I 2=0 \%\right)$, overall heterogeneity $(P=0.04$, $12=43 \%)$. There was no significant change in the outcome of the $\geq 16$-hour group after the fixed-effect model test, and the difference in the subgroup was statistically significant.Although the overall difference was statistically significant, there was only one phase study in the 8-16 hour group, so the three subgroups could not be combined and counted, and only each subgroup could be analyzed independently. The 8-16hour group was a multi-center randomized controlled trial, with a large sample size and high quality of evidence. The difference was not statistically significant, indicating that prone ventilation and supine ventilation had no significant difference in $3 \mathrm{M}$ mortality. Three studies were included in the $<8$ hours group, and the difference was not statistically significant, indicating that prone ventilation in this group had no significant benefit on $3 \mathrm{M}$ mortality. When all studies in the $\geq 16$-hour group were excluded one by one and then replotted for sensitivity analysis, the results of this subgroup were stable, so it was considered that in the fatality rate statistics for 3 months or longer, only the duration of ventilation in prone position $\geq 16$ hours per day was significantly beneficial. The forest map is shown in Figure 4 , and the funnel map is shown in Figure 6

\section{Discussion}

\subsection{The significance of this study}

Prone position ventilation has been recommended as a guide in the weak level of diagnosis and treatment of ARDS treatment ${ }^{[5]}$, ICU in foreign countries has been widely adopted, but consider its side effects in China, using relatively conservative, Although a large number of literatures have shown that it can improve oxygenation in the short term, some reports on the prognosis of ARDS show that ventilation over 16 hours is only meaningful. In this study, the short-term CFR and long-term CFR were divided into $28 \mathrm{~d}$ and $3 \mathrm{M}$ according to the statistical time of CFR. The Cochrane systematic evaluation method was used to objectively and comprehensively evaluate the influence of prone ventilation at different times of the day on the short-term and long-term CFR.

Page $4 / 11$ 
3.1.1 Influence of prone position ventilation time on 28-day fatality rate

According to the statistical analysis of the study, prone ventilation significantly benefited the mortality in the short term (28d), regardless of the duration of ventilation.

3.1.2 Influence of prone position ventilation time on 3-month mortality

The effect of prone ventilation on long-term (3M) mortality was weakened, and only patients with more than 16 hours of ventilation could benefit significantly.

\subsection{Limitations of this study}

Including :(1) the implementation plan, severity of the disease, etiology, complications and other treatment and nursing measures of prone ventilation among studies in the literature are different;(2) The description of random distribution of some included literatures is not clear, the quality of evidence is not the same, and there is heterogeneity;(3) The statistical outcome indicator time of individual studies is not accurate;(4) There are many literatures included in China with small sample size, but few studies with multi-center, large sample size and high quality.(5) The overall sample size is relatively small;(6) In the CFR statistics over 3 months, there were only 3 studies in the <8 hour group and 1 study in the 8-16 hour group, and the number of studies was too small.These limitations may lead to bias of meta-analysis results, thus affecting the reliability of meta-analysis results.

\section{Conclusion}

Meta analysis results of this study show that prone ventilation can reduce short-term (28d) mortality of ARDS patients, but it has less effect on long-term (3M or more) mortality. Only prone ventilation duration of more than 16 hours per day can significantly benefit patients. This study provides us with evidence-based medical evidence that the daily ventilation duration should be greater than 16 hours for ARDS during prone ventilation in the future.

This paper is unfunded.

\section{Abbreviations}

ARDS: Acute respiratory distress syndrome; PPV: Prone position ventilation; ALI: Acute lung injury; CFR: Case fatality rate;28 d:28 day;3M:3 month

\section{Declarations}

\section{Ethics approval and consent to participate}

Not applicable.

\section{Consent for publication}

Not applicable.

\section{Availability of data and materials}

The datasets used in this study were extracted from the included studies.

\section{Competing Interests}

The authors declare that they have no competing interests.

\section{Funding}

The study did not receive any specific funding from public, commercial or non-profit funding agencies.

\section{Authors' contributions}

$\mathrm{Ba}$ CR has full access to all data in the study and is responsible for the integrity of the data and the accuracy of the data analysis. Research concept and design and manuscript drafted by Ba CR. Research literature screening $₫$ data extraction $\square$ assess quality and statistical analysis: 
Ba CR, Wang XQ. All authors participated in data interpretation and read the manuscript carefully and approved the final version.

\section{Acknowledgements}

We would like to thank the authors of each study for their contributions in collecting and publishing relevant data.

\section{References}

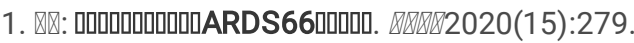

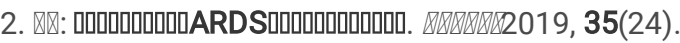

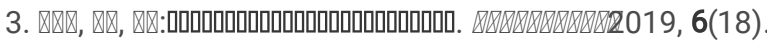

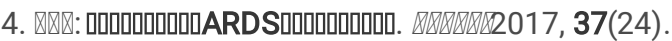

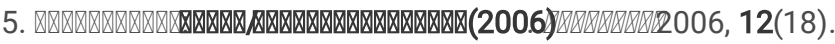

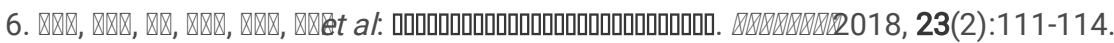

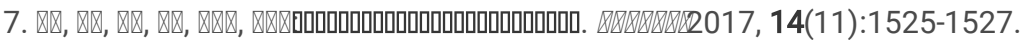

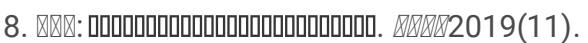

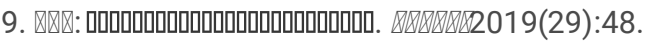

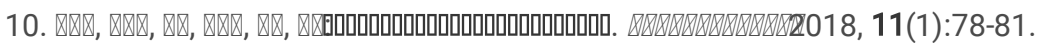

11. Guérin C, Reignier J, Richard JC, Beuret P, Gacouin A, Boulain T et al: Prone positioning in severe acute respiratory distress syndrome. New England journal of medicine 2013, 368(23):2159-2168.

12. Taccone $\mathrm{P}$, Pesenti A, Latini R, Polli F, Vagginelli F, Mietto $\mathrm{C}$ et al: Prone positioning in patients with moderate and severe acute respiratory distress syndrome: a randomized controlled trial. Jama 2009, 302(18):1977-1984.

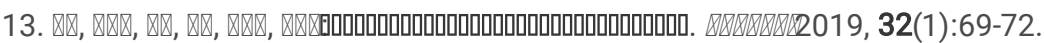

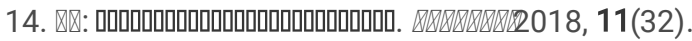

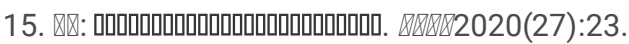

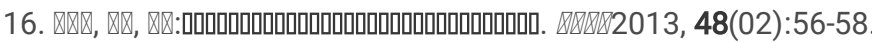

17. Mancebo -J, Fernández -R, Blanch -L, Rialp -G, Gordo -F, Ferrer -M et al: - A multicenter trial of prolonged prone ventilation in severe acute respiratory distress syndrome, vol. - 173; 2006.

18. Guerin C, Gaillard S, Lemasson S, Ayzac L, Girard R, Beuret P et al: Effects of systematic prone positioning in hypoxemic acute respiratory failure: a randomized controlled trial. JAMA 2004, 292(19):2379-2387.

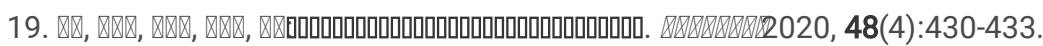

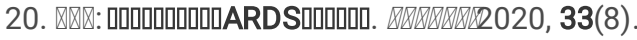

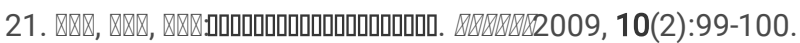

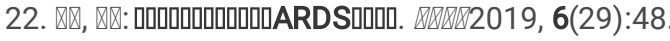

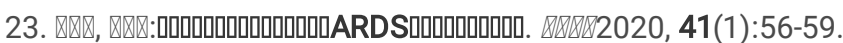

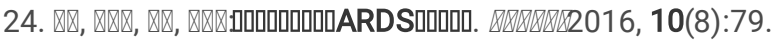

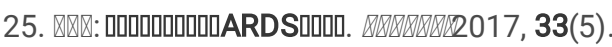

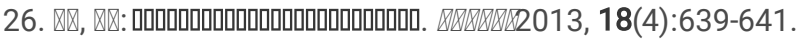

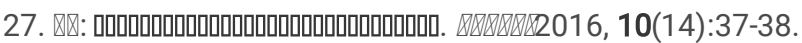

28. Beuret P, Carton MJ, Nourdine K, Kaaki M, Tramoni G, Ducreux JC: Prone position as prevention of lung injury in comatose patients: a prospective, randomized, controlled study. Intensive Care Med 2002, 28(5):564-569.

29. Gattinoni -L, Tognoni -G, Pesenti -A, Taccone -P, Mascheroni -D, Labarta - $V$ et al: - Effect of prone positioning on the survival of patients with acute respiratory failure, vol. - 345; 2001.

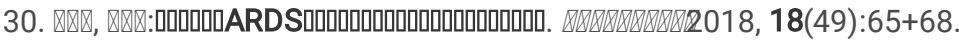

31. Fernandez R, Trenchs X, Klamburg J, Castedo J, Serrano JM, Besso G et al: Prone positioning in acute respiratory distress syndrome: a multicenter randomized clinical trial. Intensive Care Med 2008, 34(8):1487-1491.

\section{Tables}

Table 1 - Basic features of the included literature 


\begin{tabular}{|c|c|c|c|c|c|c|c|c|c|c|c|c|}
\hline \multirow{3}{*}{$\begin{array}{l}\text { Research } \\
\text { object } \\
\text { هष2017 [7] }\end{array}$} & \multirow{3}{*}{$\begin{array}{l}\text { Country } \\
\text { China }\end{array}$} & \multicolumn{3}{|c|}{ Case number } & \multicolumn{2}{|c|}{ Sex冈M/F』 } & \multicolumn{2}{|c|}{ Age $₫ X \pm S \rrbracket$} & \multicolumn{3}{|c|}{$\begin{array}{l}\text { intervention } \\
\text { measures }\end{array}$} & \multirow[t]{2}{*}{$\begin{array}{l}\text { results of } \\
\text { indicators }\end{array}$} \\
\hline & & $\mathrm{T}$ & $c$ & & $\mathrm{~T}$ & C & $\mathrm{T}$ & C & $\mathrm{T}$ & \multicolumn{2}{|c|}{$\mathrm{C}$} & \\
\hline & & 33 & 31 & & 15/18 & $17 / 14$ & $49.2 \pm 18.1$ & $47.8 \pm 16.9$ & $P$ & S & $\mathrm{Qu}$ & \\
\hline$\Delta \mathbb{2 0 1 9 ^ { [ 8 ] }}$ & China & 29 & 29 & & 15/14 & $16 / 13$ & $41.5 \pm 12.5$ & $41.5 \pm 13.5$ & $P$ & S & $\mathrm{Qu}$ & \\
\hline $\mathbb{Q} \mathbb{2} 2020^{[1]}$ & China & 33 & 33 & & 19/14 & $20 / 13$ & $49.21 \pm 2.18$ & $49.53 \pm 2.31$ & $P$ & S & 吅 & \\
\hline$\Delta \square \square 2019^{9]}$ & China & 25 & 25 & & $6 / 9$ & $14 / 11$ & $38.11 \pm 11.84$ & $35.36 \pm 10.02$ & $P$ & S & $\mathrm{Qu}$ & \\
\hline$\Delta \otimes 2019^{[2]}$ & China & 36 & 36 & & $2 / 14$ & $24 / 12$ & $54.23 \pm 4.64$ & $53.92 \pm 4.43$ & $\mathrm{P}$ & S & प्र & \\
\hline$\Delta \square \otimes 2008^{[10]}$ & China & 25 & 21 & & 17/8 & $16 / 5$ & $53.2 \pm 14.6$ & $51.7 \pm 15.5$ & $P$ & S & 吅 & \\
\hline $\mathbb{B} \mathrm{B} \times 201 \not 4]$ & China & 19 & 19 & - & - & - & - & - & $P$ & S & 吅 & \\
\hline Guerin2013 ${ }^{[11]}$ & France & 237 & 229 & & 66/71 & $152 / 77$ & $58 \pm 16$ & $60 \pm 16$ & $P$ & S & 吅 & \\
\hline Taccone2009[12] & France & 168 & 174 & - & - & - & - & - & $P$ & S & 吅 & \\
\hline $\mathbb{8} \mathbb{2} 2019^{[13]}$ & China & 13 & 30 & & $4 / 9$ & $11 / 19$ & $43.2 \pm 6.4$ & $39.5 \pm 9.3$ & $P$ & S & [ & \\
\hline $\mathbb{Q} 2018^{[14]}$ & China & 20 & 20 & & $/ / 11$ & $10 / 10$ & $35.55 \pm 3.48$ & $36.05 \pm 3.97$ & $P$ & S & ] & \\
\hline $\mathbb{8} \mathbb{2} 2020^{[15]}$ & China & 25 & 25 & & $6 / 9$ & $14 / 11$ & $38.11 \pm 11.85$ & $36.35 \pm 10.52$ & $P$ & S & ] & \\
\hline 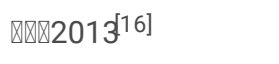 & China & 15 & 15 & - & - & - & - & - & $\mathrm{P}$ & S & ] & \\
\hline Mancebo2006 $6^{[17]}$ & Spain & 76 & 60 & - & - & - & - & - & $P$ & S & ] & \\
\hline Guerin2004 $4^{[18]}$ & France & 413 & 378 & - & - & - & - & - & $P$ & S & $\mathrm{Qu}$ & \\
\hline$\triangle \otimes 2020^{[19]}$ & China & 32 & 30 & & 18/14 & $16 / 14$ & $57.09 \pm 7.43$ & $56.62 \pm 7.25$ & $P$ & S & ] & \\
\hline$\Delta \otimes \mathbb{2 0 2 \delta ^ { 2 0 ] }}$ & China & 52 & 52 & & $35 / 17$ & $30 / 22$ & $55.5 \pm 6.34$ & $57 \pm 6.58$ & $P$ & S & ] & \\
\hline 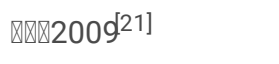 & China & 18 & 24 & - & - & - & - & - & $P$ & S & ] & \\
\hline $\mathbb{Q} 2019^{[22]}$ & China & 100 & 100 & & $51 / 49$ & $47 / 53$ & $61.47 \pm 4.09$ & $62.44 \pm 4.57$ & $P$ & S & ] & \\
\hline 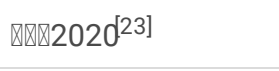 & China & 34 & 34 & & 20/14 & $18 / 16$ & $45.32 \pm 10.24$ & $46.04 \pm 10.13$ & $P$ & S & ] & \\
\hline $\mathbb{Q} 2016^{[24]}$ & China & 12 & 12 & - & & - & - & - & $P$ & S & 口 & \\
\hline 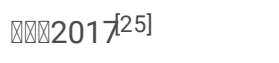 & China & 80 & 80 & & $45 / 65$ & $46 / 34$ & - & - & $P$ & $S$ & ] & \\
\hline $\mathbb{B} \otimes 2018^{[6]}$ & China & 12 & 12 & - & & - & - & - & $P$ & $S$ & ] & \\
\hline $\mathbb{Q} 2013^{[26]}$ & China & 49 & 49 & & $29 / 20$ & $27 / 22$ & $43.2 \pm 11.4$ & $45.6 \pm 12.7$ & $P$ & S & 口 & \\
\hline $\mathbb{B} 2016^{[27]}$ & China & 22 & 22 & - & & - & - & - & $P$ & $S$ & 口 & \\
\hline Beuret2002 $2^{[28]}$ & France & 25 & 26 & - & - & - & - & - & $P$ & $S$ & 吅 & \\
\hline Gattinoni [29] & Italy & 152 & 152 & - & - & - & - & - & $P$ & $S$ & 吅 & \\
\hline 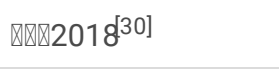 & China & 52 & 52 & & $24 / 28$ & $25 / 27$ & $59.37 \pm 4.13$ & $58.74 \pm 4.32$ & $P$ & $S$ & ] & \\
\hline Fernandez2008[31] & Spain & 21 & 19 & & $2 / 9$ & $13 / 6$ & $53.9 \pm 17.9$ & $55.3 \pm 14.6$ & $P$ & $S$ & 口 & \\
\hline
\end{tabular}

Note: T experimental group;C Control group;P prone position;S supine position;28d case fatality rate $3 \mathrm{M}$ case fatality rate 
Figures

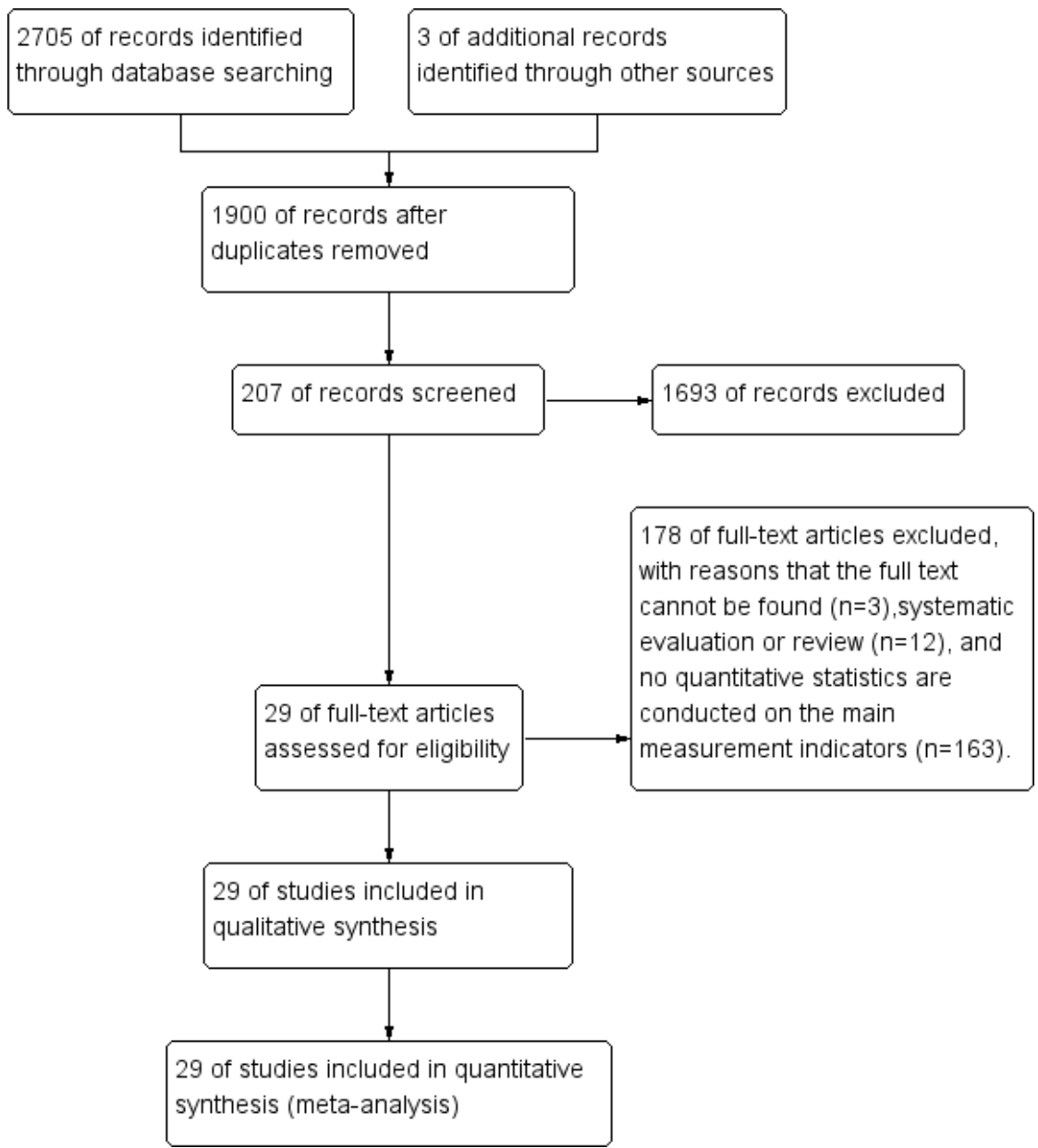

Figure 1

Literature screening flow chart

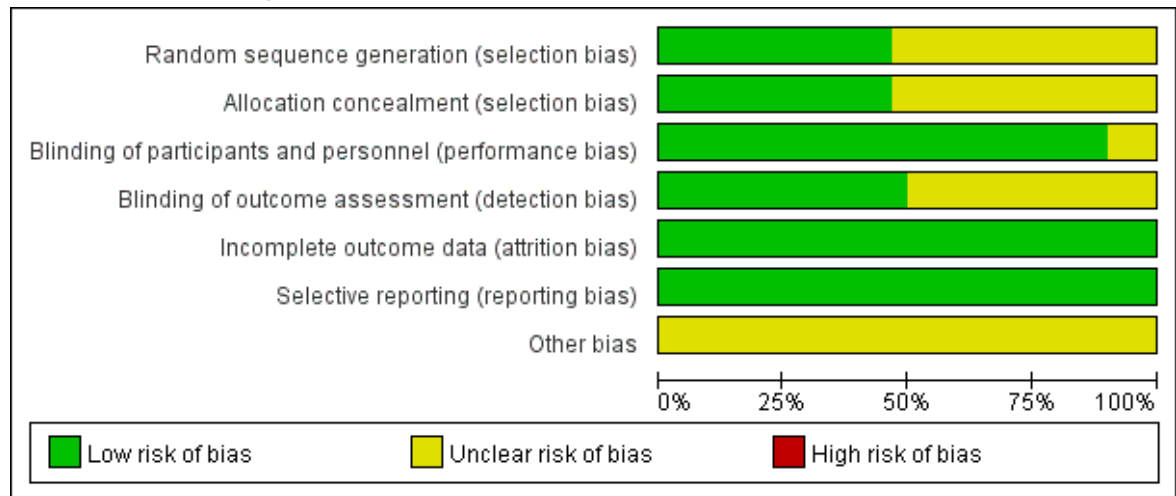

\section{Figure 2}

Bias risk assessment diagram 
傍卧位仰卧位 Odds Ratio

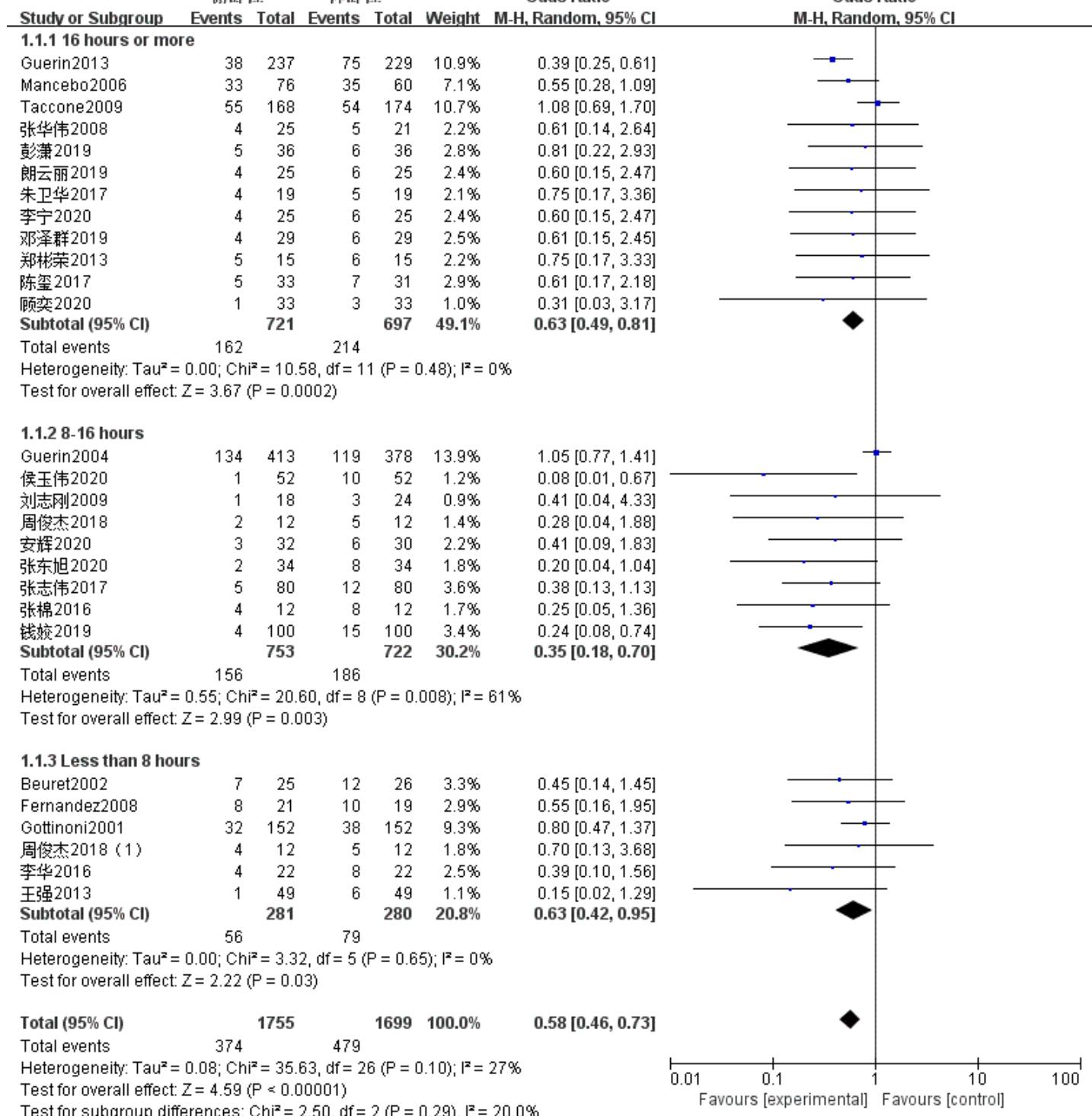

\section{Figure 3}

Forest chart of case fatality rate on $28 \mathrm{~d}$ 


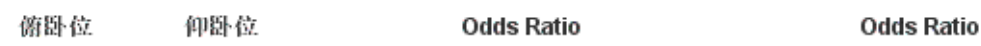

Studv or Subgroup Events Total Events Total Weight M-H, Random, 95\% C 1.3.1 16 hours or more

Guerin2013

Taccone 2009

$\begin{array}{lllll}56 & 237 & 94 & 229 & 15.0 \%\end{array}$

刘颖2018

张华伟2008

彭潇2019

朗云丽2019

未卫华2017

李亮2019

双叕群 2019

陈等 2017

顾奕2020

Subtotal $(95 \% \mathrm{Cl})$

Total events

$79 \quad 168$

$91 \quad 174 \quad 14.4 \%$

$0.44[0.30,0.66]$

$0.81[0.53,1.24]$

$1.59[0.24,10.70]$

$0.63[0.18,2.18]$

$0.74[0.25,2.17]$

$0.69[0.21,2.28]$

$0.81[0.22,2.91]$

$0.86[0.07,10.38]$

$0.40[0.12,1.36]$

$0.31[0.10,0.96]$

$0.47[0.08,2.75]$

$0.59[0.46,0.75]$

Heterogeneity: $\operatorname{Tau}^{2}=0.00 ; \mathrm{Chi}^{2}=7.41, \mathrm{df}=10(P=0.69) ; \mathrm{I}^{2}=0 \%$

Test for overall effect: $Z=4.24$ ( $\mathrm{P}<0.0001$ )

\subsubsection{8-16hours}

\section{Guerin2004}

Subtotal $(95 \% \mathrm{Cl})$

Total events

$\begin{array}{lllll}179 & 413 & 159 & 378 & 17.6 \% \\ & \mathbf{4 1 3} & & 378 & \mathbf{1 7 . 6 \%}\end{array}$

$1.05[0.79,1.40]$

$1.05[0.79,1.40]$

Heterogeneity Not applicable

Test for overall effect: $Z=0.36(P=0.72)$

1.3.3 Less than 8 hours

Beuret2002

Gottinoni2001

周志剑2018

Subtotal $(95 \% \mathrm{Cl})$

Total events

$\begin{array}{rrrrr}15 & 25 & 12 & 26 & 5.0 \% \\ 95 & 152 & 89 & 152 & 13.7 \% \\ 1 & 52 & 7 & 52 & 1.6 \% \\ & \mathbf{2 2 9} & & \mathbf{2 3 0} & \mathbf{2 0 . 3} \%\end{array}$

$$
\begin{aligned}
& 1.18[0.74,1.87] \\
& 0.13[0.01,1.06] \\
& \mathbf{0 . 9 6}[\mathbf{0 . 3 7}, \mathbf{2 . 5 1 ]}
\end{aligned}
$$

$1.75[0.58,5.32]$

Heterogeneity: Tau $^{2}=0.41 ; \mathrm{Chi}^{2}=4.76, \mathrm{df}=2(\mathrm{P}=0.09) ; \mathrm{I}^{2}=58 \%$

Test for overall effect: $Z=0.09(P=0.93)$

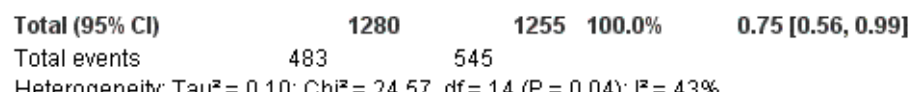

Heterogeneity: $\operatorname{Tau}^{2}=0.10 ; \mathrm{Chi}^{2}=24.57, \mathrm{df}=14(\mathrm{P}=0.04) ; \mathrm{I}^{2}=43 \%$

Test for overall effect: $Z=2.02(P=0.04)$

Test for subaroun differences: $C^{2}=9.50 . d f=2(P=0.009) . I^{2}=78.9 \%$

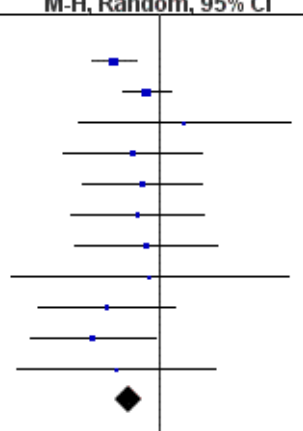

Figure 4

3M CFR forest map

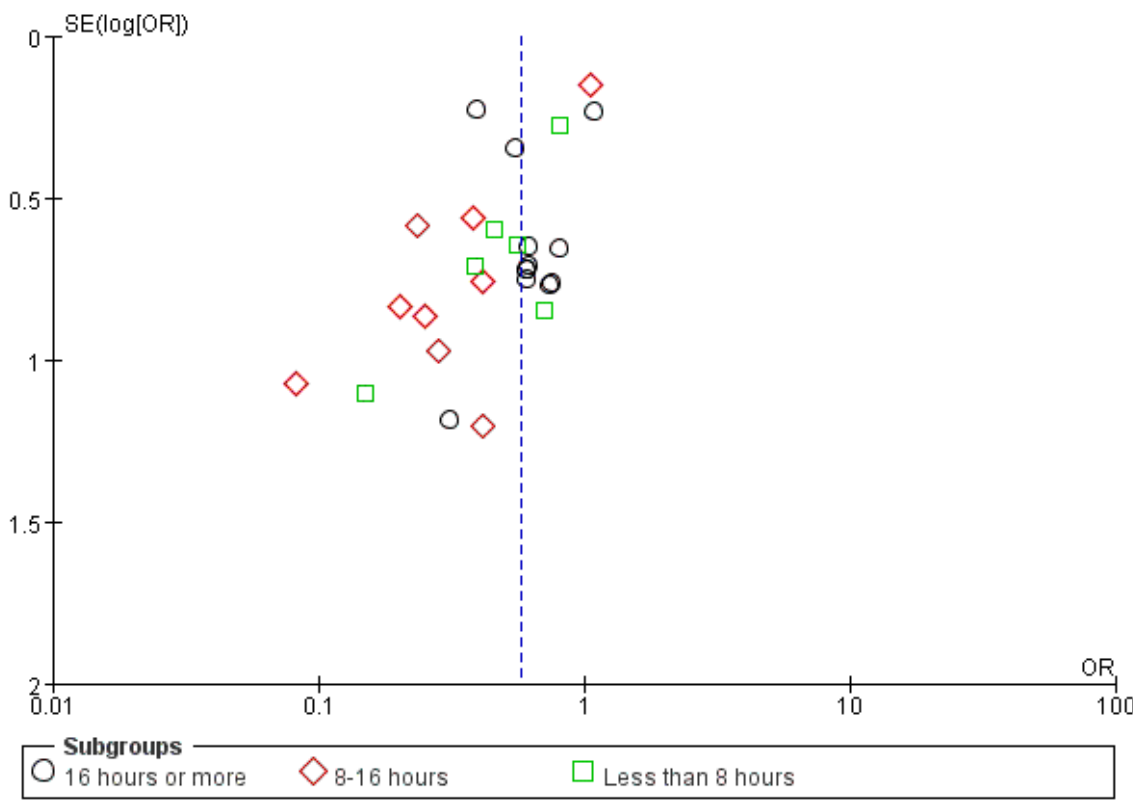

Figure 5

28d CFR funnel figure 


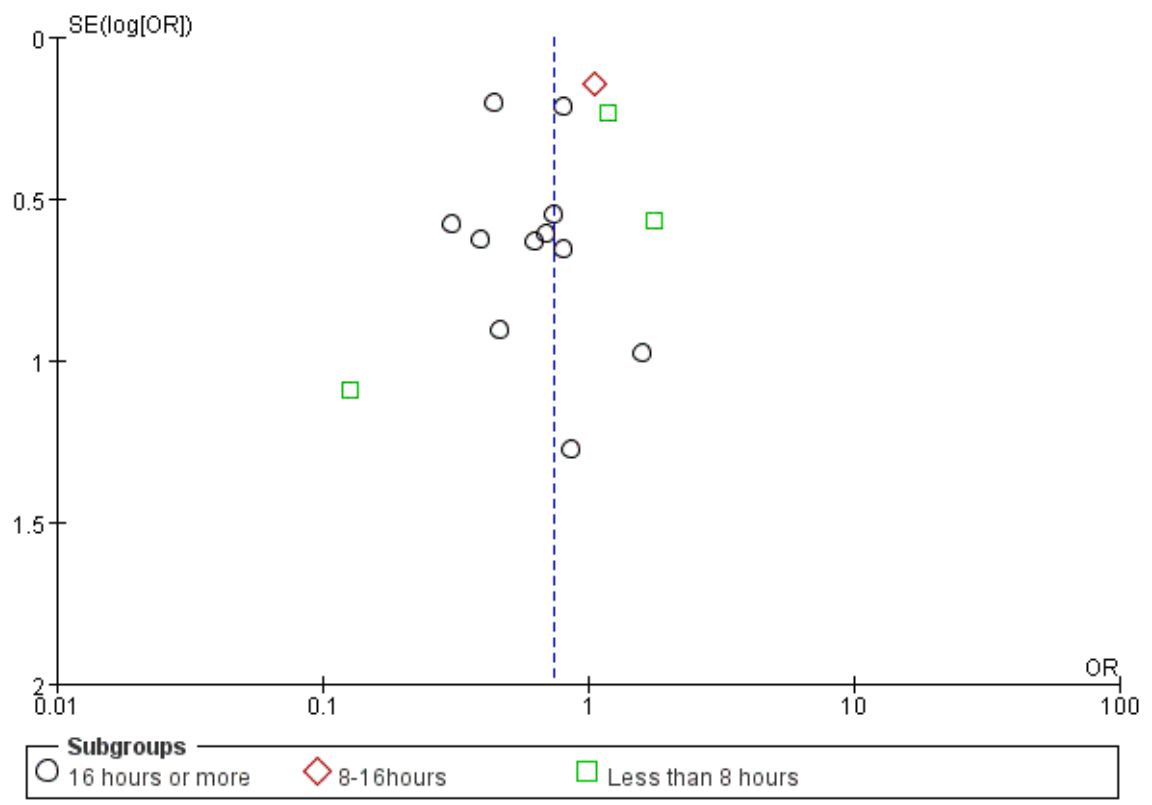

Figure 6

3M CFR funnel figure 